\title{
ESTRATIFICAÇÃO SOCIOOCUPACIONAL PARA ESTUDOS DE MERCADO E PESQUISA SOCIAL NO BRASIL
}

\author{
Paulo de Martino Jannuzzi
}

\begin{abstract}
Resumo: Com o objetivo de trazer uma contribuição metodológica aos estudos de mercado e pesquisa social no país, apresenta-se uma proposta de classificação das ocupações brasileiras em cinco estratos socioocupacionais, inspirada em estudo clássico de estratificação social inglês e baseada em indicadores empíricos de status socioeconômico, computados a partir de Censos Demográficos e PNADs.

Palavras-chave: ocupação; classificação socioocupacional; segmentação socioeconômica.
\end{abstract}

Abstract: With the objective of making a methodological contribution to market and social research in Brazil, this essay proposes the classification of occupations in Brazil into five socio-occupational strata. The inspiration for this system is classic British social stratification research, and it is based on empirical indicators of socioeconomic status, computed on the basis of Demographic Census research and PNADs.

Key words: occupation; socio-occupational classification; socio-economic segmentation.

A identificação da inserção social dos indivíduos na sociedade com a posição por eles desempenhadas no mercado de trabalho tem larga tradição nos estudos de Estratificação Social. Seja nos estudos de inspiração marxista - em que as relações de classe estariam determinadas pelas relações de produção, manifestadas pela posse ou não dos meios de produção -, seja nas abordagens weberianas - em que a estrutura de classes resultaria das desigualdades de oportunidades dos indivíduos diante do mercado -, a ocupação se constituiria em um constructo operacional básico para identificação da posição dos indivíduos e suas famílias na pirâmide social (Jorrat, 1998; Scalon, 1999). A ocupação exercida, inserção no processo produtivo, posse ou não dos meios de produção, seriam, pois, critérios clássicos para estratificação social dos indivíduos e suas famílias.

Ainda que com larga tradição nos EUA, tal identificação - posição no mercado de trabalho como posição do indivíduo na pirâmide social - não tem sido empregada na Pesquisa Social brasileira e menos ainda nos estudos de Segmentação de Mercado no país. Como bem observam Mattar (1994) e Santos e Rimoli (1995), a segmentação do mercado consumidor no Brasil pode ser descrita segundo alguns poucos recortes básicos, baseados em critérios geográficos e poder de consumo. Nem mesmo a segmentação com base em critérios demográficos tem sido empregada com a recorrência que se poderia, em que pese a relativa abundância de informações a esse respeito e a intensidade das mudanças dessa dimensão do mercado consumidor brasileiro (Jannuzzi, 1994, 1997, 2001a).

A primazia dos critérios geográficos e poder de consumo nos estudos acadêmicos e aplicações de mercado certamente se justifica pela dimensão territorial e pela persistência do grau de desigualdade socioeconômico no país, questão fartamente documentada na literatura econômica nacional. As desigualdades regionais e de renda são tão intensas que praticamente "cegam" os analistas de mercado quanto à importância de outros critérios de segmentação. Esse privilegiamento analítico acaba sendo reforçado, inclusive, pela constatação dos efeitos sobre o consumo de alimentos, eletroeletrônicos e outros produtos, por ocasião da implementação de medidas econômicas com algum impacto redistributivo ou de estímulo às atividades econômicas no país ou regiões (como o aumento do salário mínimo, diminuição de juros, implantação de uma grande indústria ou projeto governamental em uma região, etc.). 
Nesse quadro, não é difícil entender por que os sistemas classificatórios baseados na posse de bens de consumo durável (como os da Associação Brasileira de Instituições de Pesquisa de Mercado - Abipeme e Associação Nacional das Empresas de Pesquisa - Anep) desfrutam de prestígio há tanto tempo nos estudos de segmentação. Contudo, pelas limitações apontadas por Mattar (1995) e Jannuzzi e Baeninger (1996), esse tipo de abordagem de segmentação tende a perder cada vez mais sua utilidade e validade na discriminação de poder e hábitos de consumo no mercado nacional. A queda da taxa real de juros, a queda dos preços relativos dos eletroeletrônicos, a concorrência no varejo deste setor e as estratégias de facilitação de compra destes produtos (pelo acesso ao crédito, formas de pagamentos, etc.), a consolidação do mercado de geladeiras, vídeos e televisores de segunda mão ampliaram de forma significativa nos anos 90 o acesso das famílias a estes bens de consumo. Em 1999, a quase totalidade das famílias brasileiras dispunham de fogão, cerca de $90 \%$ de televisão, mais de $80 \%$ dispunha de geladeira. Com tal massificação de bens fica clara a perda gradativa do poder discriminatório da escala Abipeme e Anep, ainda que seus defensores sempre possam argumentar que é possível recalcular os pesos atribuídos aos produtos ou às quantidades, incluir um novo bem (microcomputador e DVD, por exemplo) ou ainda incorporar o ano e marca do produto no sistema de ponderação. Não bastasse isso, outro fator que conspira contra a validade dessas escalas referidas a posse de bens duráveis de médio prazo é a diminuição, dentre o conjunto da população brasileira, da importância relativa da família nuclear tradicional (casal e 2 ou mais filhos), padrão em que se baseiam essas escalas. $\mathrm{O}$ aumento de pessoas vivendo sós (muitas das quais com elevada renda), de casais sem filhos, de famílias uniparentais, famílias em ciclo vital mais adiantado (para as quais o consumo de produtos começa a ceder lugar a serviços) coloca em xeque a pertinência de se medir o poder de compra pela variedade e quantidade de eletroeletrônicos (e/ou automóveis).

É necessário, pois, oferecer uma alternativa metodológica consistente para segmentação socioeconômica do mercado consumidor brasileiro, que garanta comparabilidade no tempo e espaço. A volta do uso da renda familiar pode ser uma alternativa, em tempos de baixa inflação. Contudo, os problemas conhecidos para levantamento dessa informação nos domicílios (diversidade de fontes e membros contribuidores, insegurança com relação ao uso que se fará com os dados declarados, etc.) ain- da são obstáculos não facilmente contornáveis. É nessa perspectiva, como propõe Mattar (1997), que a segmentação socioocupacional pode ser útil, além de constituir, por ela mesma, um critério de discriminação de estilos de vida e valores socioculturais específicos de grupos sociais. O próprio autor chegou a propor um critério híbrido de segmentação de mercado, combinando indicadores de poder de compra e posição do chefe da família na ocupação (empregador, empregado, autônomo, etc.).

Procurando contribuir para o aprofundamento dos estudos de segmentação no país, o presente texto traz uma metodologia para segmentação socioocupacional do mercado consumidor brasileiro. Para isso, primeiramente são apresentados dois índices socioeconômicos para as ocupações brasileiras. Em seguida, com base nesses índices e outros indicadores ocupacionais, é apresentada a escala socioocupacional, isto é, a proposta de agregação das ocupações brasileiras em cinco grandes estratos.

\section{STATUS SOCIOECONÔMICO DAS OCUPAÇÕES BRASILEIRAS}

Como discutido em trabalho anterior (Jannuzzi, 1999), há várias metodologias sugeridas e empregadas para construção de um índice socioeconômico para ocupações e classificações socioocupacionais. Diferenciam-se pelas variáveis consideradas como critérios de ordenamento socioeconômico, pelas métricas com que as mesmas são expressas, pelas variáveis-controle consideradas, pela maior ou menor cobertura da fonte de dados usada para extrair as características ocupacionais, pelas técnicas estatísticas usadas e por outras decisões operacionais de menor alcance. Tal como em outras práticas de pesquisa nas Ciências Sociais, essas decisões metodológicas envolvem escolhas pragmáticas e preferências subjetivas do pesquisador, que podem conspirar contra a inteligibilidade, clareza interpretativa e validade do indicador produzido (em representar operacionalmente o constructo "status socioeconômico").

Um tipo particular de classificação ocupacional, de larga tradição nos estudos desta natureza por parte de autores anglo-saxões, é aquela que procura agrupar as ocupações segundo suas similaridades de nível de rendimento proporcionado e de escolaridade requerida (ou observada), denominadas de escalas socieconômicas de ocupações ou ainda escalas socioocupacionais. Com base em uma medida sintética - derivada da combinação do rendimento e escolaridade por algum método -, as 
ocupações são agrupadas e hierarquizadas em estratos ou categorias de diferentes status socioeconômico.

Status socioeconômico de uma ocupação corresponde, pois, ao prestígio social conferido pela população às ocupações ou à posição relativa da ocupação em um ranking classificatório ordenado por algum indicador socioeconômico simples ou composto como rendimento proporcionado, nível de qualificação típico das ocupações, escolaridade da mão-de-obra nelas alocada ou mesmo uma combinação destas dimensões (Valle Silva, 1978, 1985; Jorrat e Acosta, 1992; Bukstein, 1997). Em tal perspectiva, por exemplo, Médico, Magistrado, Professor seriam consideradas ocupações de maior status que as de Trabalhador Rural, Pedreiro ou Empregado Doméstico, já que na percepção subjetiva da sociedade seriam dotadas de maior prestígio social, assim como também apresentam indicadores objetivos de rendimento e escolaridade mais elevados.

Uma das propostas metodológicas para construção de índices socioeconômicos de ocupações, que procura privilegiar a simplicidade técnica e facilidade interpretativa, garantindo - em tese - a validade de constructo da medida final, é a empregada por Jorrat e Acosta (1992) na computação de indicador semelhante para as ocupações na Argentina. ${ }^{1}$ Por essa metodologia, o índice computado para uma ocupação corresponde a uma medida de posição relativa da mesma em um intervalo de 0 a 100. Mais precisamente o índice socioeconômico posicional (Isep) corresponde à porcentagem de indivíduos ocupados cujos níveis médios combinados de rendimento e escolaridade são menores ou iguais aos da ocupação considerada. Assim, um Isep de $82 \%$ para uma determinada ocupação como é o caso dos Protéticos em 1991 - significa que o conjunto de trabalhadores aí classificados apresenta um nível médio combinado de rendimento e escolaridade superior a $82 \%$ da população ocupada. Uma ocupação com Isep de 25\% - como os Serventes de Pedreiro em 1991 tem status socioeconômico mais baixo, já que os trabalhadores aí classificados teriam um nível combinado médio de rendimento e escolaridade superior a um contingente menor de ocupados (25\%).

Para construção do Isep relativo às ocupações registradas em cada base de microdados - Censos de 1980 e 1991 e Pesquisas Nacionais por Amostra de Domicílios (PNADs) dos anos 90 - computaram-se, primeiramente, para cada ocupação, as medianas de escolaridade e rendimento do trabalho principal das pessoas ocupadas de 15 a 64 anos, trabalhando 40 ou mais horas, com rendimentos válidos e escolaridade conhecida. ${ }^{2}$ Depois, calcularam-se medidas de posição relativas das ocupações segundo a escolaridade mediana observada, com base na distribuição de freqüências acumuladas das pessoas alocadas em cada posto de trabalho, ordenadas segundo o nível de escolaridade. Repetiu-se o mesmo procedimento usando como critério de ordenamento o rendimento mediano. O Isep é, então, calculado como média aritmética das duas medidas de posição relativas, daí porque ele representaria o status médio combinado de rendimento e escolaridade.

Como se poderia esperar, as ocupações de maior status - em qualquer dos três momentos - são as ocupações de nível superior, cargos da Alta Administração Pública e em postos de direção. Refletindo a estreiteza do cume da pirâmide social brasileira, essas ocupações apresentam Iseps acima de $90 \%$. Na base do índice, com Isep inferior a 20\%, estão as ocupações manuais, na Agropecuária, Extrativismo e Serviços Domésticos, isto é, ocupações de baixa escolaridade e rendimento. Valores intermediários de Isep correspondem às ocupações técnicas, de escritório, no comércio e semiqualificadas (Jannuzzi, 2001b).

Uma outra estratégia para construção de um índice de status, que procura incorporar a "distância socioeconômica" entre as ocupações e não apenas a sua posição ordinal relativa, baseia-se na utilização de métodos multivariados de "redução" de dados, empregada por Scalon (1999) e por Ribeiro e Lago (2000) em grupos ocupacionais já agregados anteriormente por outros critérios substantivos. Nessa metodologia, duas ocupações com índices próximos devem apresentar níveis também próximos de rendimento e escolaridade medianos. Uma diferença grande entre os índices computados para duas ocupações, ao contrário, reflete um "distanciamento" significativo entre os níveis de rendimento e/ou escolaridade das mesmas.

Do ponto de vista metodológico, a idéia básica nessa metodologia é computar um índice a partir do escore fatorial da primeira componente principal, obtida através da aplicação da análise de componentes principais sobre as duas dimensões socioeconômicas anteriormente explicitadas - rendimento e escolaridade medianos. Como essas dimensões são, em geral, altamente correlacionadas, a primeira componente principal tem capacidade de representar a maior parte da variabilidade do conjunto de dados (em rendimento e escolaridade entre as ocupações), o que garante o emprego dos escores referentes a cada ocupação como uma medida sintética das duas variáveis. ${ }^{3}$ Como os escores podem variar em um intervalo amplo, 
com valores positivos e negativos, mediante uma transformação matemática simples, pode-se fazer correspondêlos a uma medida entre 0 e 1 (ou 0 a 100). Aplicando-se a técnica sobre as três bases de dados separadamente, tomando-se os escores fatoriais sobre a primeira componente principal (cujo poder explicativo da variabilidade foi de $84 \%, 86 \%$ e $87 \%$, para os Censos 80,91 e as PNADs dos anos 90 , respectivamente) e transformando-os para o intervalo de 0 a 1 , obtiveram-se estimativas do Índice Socioeconômico Distancial (Ised) para cada ocupação em 1980, 1991 e 1996. Dado que o Ised apresenta forte correlação com o Isep (ainda que não linear), as posições relativas das diversas ocupações no espectro ocupacional são basicamente as descritas anteriormente.

\section{AS CATEGORIAS SOCIOOCUPACIONAIS}

Com base na ordenação das ocupações proporcionada pelos índices socioeconômicos obtidos para 1991, em indicadores de precarização dos postos de trabalho construídos com base nas informações disponíveis nas PNADs dos anos 90, na tipologia de grupos ocupacio- nais de Valle Silva (1992) organizados segundo diversos critérios substantivos (diferenças e similaridades das ocupações em relação ao caráter urbano/rural, manual/ não-manual, aos setores de atividade - serviços, indústrias modernas e tradicionais -, nível de qualificação técnicos, profissionais de nível superior -, nível de controle e autonomia - empregador, empregado e conta própria), na proposta metodológica de estratificação social segundo grupos ocupacionais de Goldthorpe (1992) e não perdendo de vista as restrições operacionais inerentes ao uso de uma pesquisa amostral como a PNAD (de qualidade da informação captada sobre ocupação e do erro amostral das estimativas) desenvolveu-se uma escala socioeconômica de cinco categorias para as ocupações brasileiras. ${ }^{4}$

O primeiro grupo social da escala compreende os indivíduos (e as famílias) na condição de grandes proprietários e as pessoas ocupadas em postos de comando, de direção ou com especialização técnica superior. Reúne, portanto, as ocupações com rendimento e escolaridade mais elevados, isto é, de maior status (Isep médio de 96\%) e menor grau de precarização. Tal estrato corresponderia

TABELA 1

Indicadores de Status Socioeconômico de Ocupações Selecionadas

Brasil - 1991

\begin{tabular}{|c|c|c|c|c|c|}
\hline Grupo Ocupacional & Isep (1) & Ised (2) & Rendimento (3) & Escolaridade (4) & Total (5) \\
\hline Administradores do comércio & 90,5 & 0,22 & 682,02 & 11 & 294.033 \\
\hline Agricultores & 60,9 & 0,09 & 363,75 & 4 & 181.254 \\
\hline Analistas de sistemas & 98,9 & 0,43 & $1.818,73$ & 15 & 58.705 \\
\hline Auxiliar administrativo & 76,5 & 0,18 & 318,28 & 11 & 1.377 .931 \\
\hline Comerciantes por conta própria & 64 & 0,09 & 409,21 & 4 & 1.060 .841 \\
\hline Administradores do serviço público & 94,2 & 0,26 & 818,43 & 12 & 148.973 \\
\hline Engenheiros & 99,6 & 0,51 & $2.273,41$ & 16 & 142.739 \\
\hline Mecânicos de veículos automotores & 62,3 & 0,09 & 313,73 & 5 & 602.156 \\
\hline Motoristas & 67,8 & 0,1 & 418,31 & 4 & 1.692 .672 \\
\hline Porteiros & 45,6 & 0,07 & 259,17 & 4 & 138.566 \\
\hline Produtores agropecuários autônomos & 19,2 & 0,03 & 136,4 & 2 & 3.454 .966 \\
\hline Professores de 1a a 4a série & 79,9 & 0,18 & 345,56 & 11 & 193.872 \\
\hline Professores de ensino superior & 99,3 & 0,44 & $1.818,73$ & 16 & 50.045 \\
\hline Serventes & 30,9 & 0,06 & 181,87 & 4 & 719.201 \\
\hline Serventes de pedreiro & 25,3 & 0,05 & 163,69 & 3 & 637.168 \\
\hline Técnicos de agropecuária & 88,4 & 0,19 & 463,78 & 11 & 31.203 \\
\hline Torneiros mecânicos & 75,9 & 0,14 & 454,68 & 7 & 136.277 \\
\hline Trabalhadores na agropecuária & 6,1 & 0,02 & 90,94 & 2 & 4.821 .211 \\
\hline Vendedores & 58,7 & 0,12 & 227,34 & 8 & 1.766 .367 \\
\hline Vigias & 43,8 & 0,07 & 250,08 & 4 & 439.336 \\
\hline
\end{tabular}

Fonte: Jannuzzi (2001b).

(1) Índice de status socioeconômico posicional.

(2) Índice de status socieconômico distancial.

(3) Rendimento mediano dos ocupados na ocupação descrita (em $R \$$ de setembro de 1999).

(4) Escolaridade mediana em anos de estudo dos ocupados na ocupação descrita.

(5) Total de ocupados na ocupação descrita na população de 15 a 64 anos com 38 ou mais horas no trabalho principal. 
QUADRO 1

Algumas Ocupações Típicas dos Estratos Socioocupacionais

\begin{tabular}{ll}
\hline $\begin{array}{l}\text { Estrato } \\
\text { Socioocupacional }\end{array}$ & Ocupações Típicas \\
\hline Alto & $\begin{array}{l}\text { Médico, Engenheiro, Professor Universitário, Empresários, Gerentes e postos superiores na Administração Pública (Juízes, Promotores, } \\
\text { Delegados, Oficiais das Forças Armadas, etc.) }\end{array}$ \\
Médio-alto & $\begin{array}{l}\text { Técnicos de contabilidade e administração, Mestre e Contramestres na indústria, Professores de ensino fundamental e médio, Corretores de } \\
\text { Imóveis, Inspetores de Polícia, Carteiros, Comerciantes (proprietários) e Agricultores }\end{array}$ \\
Médio & $\begin{array}{l}\text { Torneiro Mecânico, Montadores de Equipamentos Elétricos, Vendedores, Operadores de caixa, Comerciantes conta-própria, Professores de } \\
\text { ensino pré-escolar, Motoristas, Inspetores de alunos, Auxiliares de enfermaria, Auxiliares administrativos e de escritório, Policiais e Praças das Forças } \\
\text { Armadas }\end{array}$ \\
Médio-baixo & $\begin{array}{l}\text { Ocupações da indústria de alimentos, ocupações da indústria têxtil, Pedreiros, Pintores, Garçons, Vigias, Porteiros, Estivadores, Vendedores } \\
\text { ambulantes }\end{array}$ \\
Baixo & $\begin{array}{l}\text { Trabalhadores rurais na condição de empregados ou autônomos (produtores meeiros ou parceiros), além das ocupações urbanas de baixo status } \\
\text { como de Serventes de Pedreiro, Lavadeiras, Empregados Domésticos e Lixeiros }\end{array}$ \\
\hline
\end{tabular}

em alguma medida ao que Goldthorpe (1992) denominou de classes de colarinho branco na classificação socioocupacional da população inglesa, nas quais se enquadrariam os indivíduos com maior poder de comando da atividade produtiva, de delegação de autoridade ou aqueles com alto grau de conhecimento especializado. Na classificação de ocupações adotada pelo IBGE são típicos representantes desse estrato social os indivíduos que exercem ocupações como de Médico, Engenheiro, Professor Universitário, Empresários, Gerentes e postos superiores na Administração Pública (Juízes, Promotores, Delegados, Oficiais das Forças Armadas, etc.). Rendimento mediano acima de R \$ 3.000, escolaridade de 16 anos ou mais, tempo médio de trabalho acima de 10 anos, baixo risco ao desemprego, são atributos comuns das ocupações aqui enquadradas.

O segundo estrato (Isep de $85 \%$ ) reúne, em boa medida, o que Goldthorpe denomina de 'pequena burguesia', isto é, os pequenos proprietários, chefes e supervisores e empregados qualificados de escritório e técnicos de média especialização na indústria e serviços. Técnicos de contabilidade e administração, Mestre e Contramestres na indústria, Professores de ensino fundamental e médio, Corretores de Imóveis, Inspetores de Polícia, Carteiros, Comerciantes (proprietários) e Agricultores são algumas das ocupações enquadradas neste grupo. Com menor poder de comando ou qualificação, tais ocupações apresentam um rendimento médio bem menor, ainda que em relação aos indicadores de escolaridade e precariedade as diferenças não sejam tão expressivas. Comparem-se, por exemplo, os indicadores de duas ocupações com relativa similaridade funcional como a de Professor Universitário (estrato socioocupacional alto) e Professor de ensino médio (estrato médio-alto): o rendimento médio dos primeiros (Professor Universitário) é cerca de $\mathrm{R} \$ 2.120$, duas vezes e meia maior que os dos últimos (R\$ 799); a escolaridade mediana é de 16 anos entre os professores de ensino superior contra 15 anos dos professores de ensino médio; a proporção de contribuintes à Previdência Pública é superior a 94\% nos dois grupos; o risco ao desemprego é inferior a $3 \%$ para os dois grupos.

O terceiro estrato (Isep de 69\%) reúne a maioria de ocupações no Comércio, Serviços e postos qualificados da Indústria, ao que se poderia associar-ainda que remotamente - a 'elite de colarinho azul' referida pelo autor. Ocupações típicas desse grupo são as de Torneiro Mecânico, Montadores de Equipamentos Elétricos, Vendedores, Operadores de caixa, Comerciantes conta-própria, Professores de ensino préescolar, Motoristas, Inspetores de alunos, Auxiliares de enfermaria, Auxiliares administrativos e de escritório, Policiais e Praças das Forças Armadas. Os indicadores de precarização ocupacional são significativamente piores: a rotatividade é muito elevada ( $46 \%$ dos ocupados estavam empregados há até 3 anos), um quarto dos ocupados aí enquadrados tem uma jornada superior a 48 horas semanais e o risco ao desemprego é maior.

O quarto grupo socioocupacional (Isep de 45\%), mais heterogêneo, compreende os empregados em prestação de serviços de baixa qualificação nos serviços, construção civil e indústria tradicional - algo que talvez se poderia associar, com alguma boa vontade - à 'classe operária' 
TABELA 2

Indicadores Socioeconômicos dos Estratos Socioocupacionais

Brasil-1991-1996

\begin{tabular}{|c|c|c|c|c|c|c|c|c|c|c|}
\hline \multirow[b]{2}{*}{$\begin{array}{l}\text { Estrato } \\
\text { Socioocupacional }\end{array}$} & \multicolumn{4}{|c|}{1991} & \multicolumn{6}{|c|}{1996} \\
\hline & $\begin{array}{l}\text { Isep } \\
\text { Média }\end{array}$ & $\begin{array}{l}\text { Isep } \\
\text { Desvio- } \\
\text { padrão }\end{array}$ & $\begin{array}{l}\text { Ised } \\
\text { Média }\end{array}$ & $\begin{array}{l}\text { Ised } \\
\text { Desvio- } \\
\text { padrão }\end{array}$ & $\begin{array}{c}\text { Contribuintes } \\
\text { Previdência } \\
(\%)\end{array}$ & $\begin{array}{c}\text { Ocupados } \\
\text { com até } \\
3 \text { Anos na } \\
\text { Ocupação } \\
(\%)\end{array}$ & $\begin{array}{c}\text { Ocupados } \\
\text { com Jornada } \\
\text { Semanal } \\
\text { Maior } \\
48 \text { horas } \\
(\%)\end{array}$ & $\begin{array}{c}\text { Fator } \\
\text { Relacionado } \\
\text { ao Risco de } \\
\text { Desemprego }\end{array}$ & $\begin{array}{l}\text { Rendimento } \\
\text { (R\$ de } \\
\text { set. 2000) }\end{array}$ & $\begin{array}{l}\text { Escolaridade } \\
\quad \text { (anos) }\end{array}$ \\
\hline Alto & 95,7 & 3,9 & 0,34 & 0,11 & 79,8 & 27,0 & 18,1 & 3,4 & $1.386,47$ & 13,2 \\
\hline Médio-alto & 85,2 & 7,1 & 0,20 & 0,04 & 73,2 & 32,1 & 18,9 & 5,9 & 687,19 & 10,5 \\
\hline Médio & 67,2 & 7,5 & 0,12 & 0,03 & 60,8 & 46,7 & 25,1 & 9,3 & 369,86 & 7,5 \\
\hline Médio-baixo & 45,2 & 9,9 & 0,07 & 0,01 & 43,8 & 49,9 & 19,9 & 11,4 & 251,35 & 4,59 \\
\hline Baixo & 14,8 & 7,5 & 0,03 & 0,01 & 12,2 & 38,5 & 22,0 & 9,7 & 121,13 & 2,48 \\
\hline
\end{tabular}

Fonte: Jannuzzi (2001b).

TABELA 3

Evolução dos Estratos Socioocupacionais da População Ocupada Brasil-1980-1996

\begin{tabular}{lrrr}
\hline Estrato Socioocupacional & 1980 & 1991 & 1996 \\
\hline Total & 100,0 & 100,0 & 100,0 \\
Alto & 4,5 & 5,5 & 5,9 \\
Médio-alto & 9,9 & 12,6 & 11,9 \\
Médio & 22,3 & 26,8 & 27,3 \\
Médio-baixo & 27,1 & 25,8 & 26,3 \\
Baixo & 36,2 & 29,3 & 28,6 \\
\hline
\end{tabular}

Fonte: Jannuzzi (2001b).

de Goldthorpe. Aqui estão reunidas as ocupações da Indústria de Alimentos, da Indústria Têxtil, Pedreiros, Pintores, Garçons, Vigias, Porteiros, Estivadores. Alguns indicadores de precarização chegam a ser ainda piores que os do estrato anterior: menos da metade contribui para a Previdência, metade tem sobrejornada e o risco ao desemprego é mais elevado.
O último grupo socioocupacional (Isep de 18\%) reúne os trabalhadores rurais na condição de empregados ou autônomos (produtores meeiros ou parceiros), além das ocupações urbanas de baixo status como a de Serventes de Pedreiro, Lavadeiras, Empregadas Domésticas e Lixeiros. Compreende pois a parcela da mão-de-obra - empregada ou autônoma - de remuneração e escolaridade mais baixa, inserida em postos de trabalho de elevada precariedade. ${ }^{5} \mathrm{O}$ caso dos Empregados Domésticos (código 807 na classificação do IBGE) é sintomático nesse sentido: pelos dados das PNADs dos anos 90, o rendimento mediano era de $\mathrm{R} \$ 136$, somente um quarto contribuía para Previdência Pública, $65 \%$ estavam no trabalho atual há menos de três anos, quase um terço tinha jornada semanal superior a 48 horas, $22 \%$ apresentavam o risco de vir a se desempregar.

Dessas observações apreende-se que o poder discriminatório dos níveis de rendimento e escolaridade na classificação das ocupações vai decrescendo dos estratos socioocupacionais mais elevados em direção aos mais baixos, crescendo, em contrapartida, a importância das

TABELA 4

Estrutura Socioocupacional, por Unidades da Federação Brasil - 1999

\begin{tabular}{lrrrrrrrr}
\hline Estrato Socioocupacional & DF & RJ & SP & RS & MG & PE & BA \\
\hline Total & 100,0 & 100,0 & 100,0 & 100,0 & 100,0 & 100,0 & 100,0 \\
Alto & 14,1 & 8,9 & 8,8 & 6,7 & 4,7 & 4,0 & 3,0 & $\mathbf{1 0 0 , 0}$ \\
Médio-alto & 17,6 & 16,2 & 15,0 & 11,4 & 10,8 & 8,8 & 8,5 \\
Médio & 29,0 & 32,0 & 31,7 & 23,4 & 22,2 & 23,0 & 16,7 & 14,4 \\
Médio-baixo & 25,5 & 30,3 & 29,2 & 27,8 & 24,9 & 26,5 & 20,5 \\
Baixo & 13,9 & 12,6 & 15,3 & 30,8 & 37,4 & 37,7 & 51,3 \\
\hline
\end{tabular}

Fonte: PNAD. 
medidas de precarização ocupacional como rotatividade, contribuição à Previdência, risco ao desemprego.

\section{TENDÊNCIAS E DIFERENCIAIS REGIONAIS}

Com base na classificação socioocupacional proposta, a estrutura social teria apresentado uma mudança significativa nos últimos 20 anos, com forte redução do grupo situado na base (como resultado da desruralização da mãode-obra) e aumento dos segmentos médios. Aparentemente, as mudanças na estrutura socioocupacional foram mais marcantes na década de 80 que nos anos 90 , como se pode verificar pela variação menos intensa entre 1991 e $1996 .^{6}$

Esse é um resultado que aponta em sentido bastante diferente daqueles mostrados por alguns estudos de segmentação baseados nas escalas Abipeme e Anep (Critério Brasil), construídas a partir da posse de bens de consumo durável. Estudos baseados nessas escalas mostram que houve um aumento significativo das classes A e B nos anos 90, o que estaria indicando uma mudança significativa da estrutura social brasileira no período. Contudo, essas mudanças refletem, na realidade, a massificação de certos produtos, conseqüência, por sua vez, do barateamento relativo dos produtos (em função da importação), de políticas mais flexíveis de acesso ao crédito para a população de baixa renda, além da recuperação do poder de compra entre 1992 e 1996. Assim, ao contrário do que propalado, a estrutura social brasileira teria tido mudanças pouco significativas nos anos 90 .

De uma perspectiva comparativa regional, as diferenças na estrutura social brasileira retratadas pela escala socioocupacional proposta mostram-se bastante expressivas. Vejam-se nesse sentido, as diferenças entre as estruturas socioocupacionais do Distrito Federal, Estado de São Paulo e do Estado do Rio de Janeiro em relação a outros Estados. As parcelas de mão-de-obra nos estratos médio-alto e alto são muito superiores às das demais áreas consideradas, como era de se esperar pelo nível e padrão de consumo apurados pelas pesquisas de mercado e auditorias de estoque no país. No DF, por exemplo, mais de $30 \%$ da força de trabalho está classificada nos estratos socioocupacionais mais elevados, enquanto, no Maranhão, para citar outro caso, menos de 10\% da mão-de-obra está aí inserida. Por outro lado, tais dados mostram também as significativas diferenças da estrutura socioocupacional pelos Estados do Nordeste. O Estado de Pernambuco, por exemplo, parece ter uma estrutura socioocupacional mais próxima de Minas Gerais do que a da Bahia. ${ }^{7}$

\section{CONSIDERAÇÕES FINAIS}

Como apontado por outros autores, a estratificação ou a segmentação socioocupacional, isto é, a subdivisão da população segundo grupos ocupacionais de status socioeconômico diferenciado, é muito pouco empregada no país. Por um lado, isso decorre da facilidade operacional e relativo poder discriminatório das escalas baseadas na posse de bens de consumo durável, características que tendem a ser cada vez mais comprometidas com a massificação da posse desses bens (e a necessidade de ampliação do número de itens e da identificação da marca e modelos, caso se queira continuar garantindo a validade das escalas). Por outro, a baixa utilização da segmentação socioocupacional nos estudos acadêmicos e aplicados no Brasil talvez decorra do desconhecimento de algumas das propostas de escalas socioocupacionais existentes, como as de Valle Silva (1992), Ribeiro e Lago (2000) e a apresentada neste texto.

Diferentemente das escalas baseadas na posse de bens de consumo, as escalas socioocupacionais derivam de concepções teóricas de larga tradição na Pesquisa Social. Seja de uma perspectiva marxista, seja de uma perspectiva weberiana, a ocupação é entendida como critério básico e estruturante da inserção social dos indivíduos na sociedade urbano-industrial. Além da superioridade teórica, as escalas socioocupacionais refletem empiricamente, como mostrado aqui, diferenciais socioeconômicos expressivos de rendimentos, escolaridade, qualidade e segurança no posto de trabalho. Ainda que operacionalmente mais complexas, essas escalas são mais robustas às variações conjunturais. Suas variações tendem a refletir mudanças de natureza estrutural e, por isto mesmo, mais lentas.

Tais características certamente fazem da classificação proposta um instrumento preferível à renda familiar e aos critérios de classificação socioeconômica existentes para estudos que necessitem de categorias de estratificação social ou segmentação socioeconômica da população brasileira.

\footnotetext{
NOTAS

1. A metodologia empregada pelos autores é a proposta em estudo clássico de Nam e Powers na década de 60.

2. O uso da mediana justifica-se pela sua característica de menor sensibilidade a dados extremos como tipicamente ocorre com a coleta de informações sobre rendimento. Seu emprego também como estimativa da tendência central da escolaridade deve-se à necessidade de garantir compatibilidade metodológica com a estimativa de rendimento
} 
e, sobretudo, consistência do cômputo da variável nas três bases de dados, já que a escolaridade foi codificada em um intervalo de 0 a 15 anos de estudo, em que a categoria de 15 anos inclui todas as demais superiores. A seleção da faixa etária de 15 a 64 anos teve o objetivo de privilegiar a parcela - majoritária - da população ocupada com inserção ocupacional mais claramente definida, seja de condição de atividade e ocupação, seja de categoria ocupacional. A consideração dos ocupados com 40 ou mais horas teve o objetivo de compatibilizar a duração da jornada sobre a qual se referia a remuneração.

3. Se as duas variáveis não fossem altamente correlacionadas não seria possível usar apenas a primeira componente como um indicador síntese das mesmas. Neste caso, a técnica recomendada seria a análise de aglomerados com o objetivo de obter não um índice, mas criar uma tipologia ou classificação.

4. A codificação da escala socioocupacional para cada ocupação é apresentada na primeira coluna da tabela do anexo em Jannuzzi (2001b).

5. O risco ao desemprego e à rotatividade do conjunto de ocupações aí inserido só não é maior certamente pelas características da mobilidade ocupacional dos trabalhadores rurais.

6. Essa assertiva parece válida mesmo levando em conta que o intervalo de tempo considerado nos anos 90 é menor.

7. Em termos mercadológicos, esses resultados sugerem a necessidade de uma nova subsegmentação geográfica na região, mais desagregada que a usualmente adotada pelo Ibope e Nielsen em suas pesquisas.

\section{REFERÊNCIAS BIBLIOGRÁFICAS}

BUKSTEIN, G. Medidas de prestígio ocupacional: aproximación a la medición del status socioeconómico de las ocupaciones. Estudios del Trabajo, Buenos Aires, v.14, p.93-114, 1997.

GOLDTHORPE, J.H. Social mobility and class structure in modern britain. New York: Oxford University Press, 1992.

JANNUZZI, P. de M. Indicadores sociais no Brasil: conceitos, fontes de dados e aplicações. Campinas: Alínea/PUC-Campinas, 2001a.

. Status socioeconômico das ocupações brasileiras: medidas aproximativas para 1980, 1991 e anos 90. Revista Brasileira de Estatística, Rio de Janeiro, v.2, n.61, p.47-74, 2001 b.

Construção de uma escala sócio-ocupacional: notas metodológicas. Revista Brasileira de Estatística, Rio de Janeiro, v.60, n.2, p.7-24, jul./dez. 1999.

. A importância das variáveis sócio-demográficas no estudo do comportamento do consumidor: uma contribuição empírica a partir da análise de pesquisa de orçamento familiar. $21^{\circ}$ ENANPAD. Anais eletrônicos... Rio das Pedras, RJ: ANPAD, set. 1997. CD-ROM.
Mercado consumidor brasileiro: primeiras evidências do Censo 91. 18 ENANPAD. Anais... Curitiba: Anpad, 1994. v.2, p.295-306.

JANNUZZI, P. de M.; BAENINGER, R. Qualificação socioeconômica e demográfica das classes da escala Abipeme. Revista de Administração, São Paulo, USP, v.31, n.3, p.82-90, 1996.

JORRAT, J.R. Modelos predominantes de estrutura de clases y su rendimiento empírico: un estudio del Area Metropolitana de Buenos Aires. Estudios del Trabajo, Buenos Aires, v.16, p.3-48, 1998.

JORRAT, J.R.; ACOSTA, L.R. Aproximaciones a la medición del status socioeconómico de las ocupaciones en Argentina. Estudios del Trabajo, Buenos Aires, v.4, p.79-106, 1992.

MATTAR, F. Novo modelo de estratificação socioeconômica para marketing e pesquisas de marketing. $2^{\circ}$ SEMEAD. Anais... São Paulo, 21 e 22 out. 1997.

. Análise crítica dos estudos de estratificação socioeconômica de ABA-Abipeme. Revista de Administração, São Paulo, v.30, n.1, p.57-74, jan./mar. 1995.

. Estratificação socioeconômica e pesquisas de marketing. $18^{\mathrm{o}}$ ENANPAD. Anais... Curitiba: ANPAD, 1994. v.2, p. 307-325.

RIBEIRO, L.C.Q.; LAGO, L.C. O espaço social das grandes metrópoles brasileiras: São Paulo, Rio de Janeiro e Belo Horizonte. Revista Brasileira de Estudos Urbanos e Regionais, Recife, v.3, p.111130, nov. 2000.

SANTOS, R.C.; RIMOLI, C.A. Uma visão sobre segmentação de mercado no Brasil. In: WEINSTEIN, A. Segmentação de mercado. São Paulo: Atlas, 1995. p.297-306.

SCALON, M.C. Mobilidade social no Brasil: padrões e tendências. Rio de Janeiro: Iuperj/Revan, 1999.

VALLE SILVA, N. Uma proposta de classificação das ocupações brasileiras. LNCC, 1992. Mimeografado.

. Atualização da escala socioeconômica de ocupações para 1980. Rio de Janeiro: LNCC, 1985 (Relatório de pesquisa e desenvolvimento).

Posição social das ocupações. Rio de Janeiro: IBGE, 1978. Mimeografado.

Paulo de Martino Jannuzzi: Professor do Mestrado em Estudos Populacionais e Pesquisas Sociais da Ence/IBGE (pjannuzzi@ibge.gov.br). 